\title{
Metachronous Carcinomas of the Biliary Tract in a Patient Treated Three Times with Curative Surgery
}

\author{
Masanao Kurata ${ }^{a}$ Atsutake Okamoto ${ }^{a}$ Tomoyoshi Suzuki $^{a}$ \\ Gaku Matsumoto $^{\mathrm{a}}$ Koji Tsuruta ${ }^{\mathrm{a}}$ Goro Honda $^{\mathrm{a}}$ \\ Tetsuo Nemoto ${ }^{b}$
}

Departments of a Surgery and ${ }^{\mathrm{b}}$ Pathology, Tokyo Metropolitan Komagome Hospital, Tokyo, Japan

\section{Key Words}

Metachronous carcinoma - Carcinoma of the biliary tract - COX-2 protein expression . Repeated resection

\begin{abstract}
We here report on a case of metachronous multicentric carcinomas of the biliary tract treated 3 times with curative surgery over 23 years. A 28-year-old woman underwent cholecystectomy because of papillary carcinoma of the gallbladder. After 17 years, 3 carcinomas developed in the biliary tract: intrahepatic cholangiocarcinoma of the left liver, common bile duct carcinoma, and remnant cystic duct carcinoma. They were successfully removed via left hepatectomy combined with pylorus-preserving pancreatoduodenectomy. Furthermore, another intrahepatic cholangiocarcinoma developed 6 years after the second surgery, which was removed again via partial resection of the posterior segment of the liver. Histological findings of carcinomas represented various grades of cell differentiation. No predisposition toward carcinogenesis was found, since neither pancreaticobiliary maljunction nor primary sclerosing cholangitis was present, and the overexpression of cyclooxygenase-2 was negative in all resected specimens. Close monitoring for recurrence is warranted for early detection of metachronous carcinoma that might be effectively treated with repeated resection.
\end{abstract}




\section{Introduction}

Carcinoma of the biliary tract sometimes displays synchronous or metachronous multicentric origins. We present the case of a patient who underwent successful repeated tumor resections for 3 different kinds of metachronous carcinoma of the biliary tract. To clarify predispositions toward carcinogenesis in the biliary tract, immunohistochemical staining was applied to the resected specimens.

\section{Case Report}

A 28-year-old woman underwent cholecystectomy in March 1979 at our hospital due to carcinoma of the gallbladder that displayed diffuse spread without lymph node involvement. The stump of the cystic duct was histologically negative for cancer cells. Histology of the tumor was papillary carcinoma

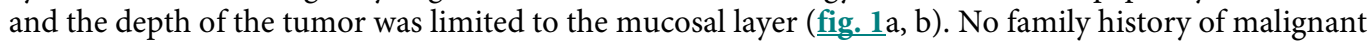
neoplasms was present.

The patient remained disease-free for 18 years after surgery, but was then hospitalized again due to epigastric pain. Laboratory data were all within normal ranges, except for serum CA19-9 at $90 \mathrm{IU} / \mathrm{ml}$. A low density area measuring $5 \times 4 \mathrm{~cm}$ was detected in the left hepatic lobe on computed tomography (CT) (fig. 2a). Furthermore, tumor shadows were observed in the common bile duct on endoscopic retrograde cholangiopancreatography. Neither pancreaticobiliary maljunction (PBM) nor primary sclerosing cholangitis (PSC) was present (fig. 2b). All tumors were successfully removed via left hepatic lobectomy combined with pylorus-preserving pancreatoduodenectomy in May 1997. Macroscopically, resected specimens displayed a variety of tumors, with a tumor arising from the remnant cystic duct and a tumor in the common bile duct identified as pedunculated polypoid tumor associated with widespread tiny granular lesions. Histology of the hepatic tumor was intrahepatic cholangiocarcinoma (ICC) that had invaded the ligamentum teres hepatis, associated with mucosal spread along the left hepatic duct, and represented poor cell differentiation, while pedunculated polypoid tumors were identified as papillary adenocarcinoma. Widespread tiny granular lesions represented severe dysplasia (ig. $3 \mathrm{a}-\mathrm{c})$.

In November 2003, follow-up CT detected a minute but gradually enlarging low-density area in the posterior segment of the liver. The tumor was removed via partial resection of the liver in February 2004. The resected tumor measured $2.1 \times 1.9 \mathrm{~cm}$ and displayed intraductal spread forming a small tumor mass. Histology of the tumor was ICC that represented moderate cell differentiation (fig. 4a, b). The patient has remained disease-free for 4 years.

Findings of histology and immunohistochemical staining for expression of p53 and cyclooxygenase$2(\mathrm{COX}-2)$ protein are summarized in table 1 . Some carcinomas showed negative p53 protein expression, but the other carcinomas were positive. COX-2 protein expression was negative in all cancer cells, non-cancerous biliary epithelial cells and mucosal dysplasia.

\section{Discussion}

The present case is extremely rare, as 3 different kinds of carcinoma developed metachronously over the course of 25 years. Long-time intervals between the onsets of the individual tumors substantially support the hypothesis that they are nonmetastatic tumors that developed independently. Additionally, they individually present different histology and cell differentiation. The exact mechanism of carcinogenesis in this patient remains unclear, since the patient displayed neither PBM nor PSC, both of which are widely accepted as strong risk factors for carcinoma of the biliary tract. Previous reports show that patients with PBM tend to have synchronous multicentric biliary carcinoma, and metachronous carcinoma sometimes develops even after resection of choledochal cyst associated with carcinoma [1-3].

To clarify the predisposition toward carcinogenesis in the biliary epithelium, immunohistochemical study was carried out. COX-2 expression has been confirmed to 
promote carcinogenesis by producing prostaglandin E2 in an intestinal polyposis model $[4,5]$, and p53 mutations are involved in carcinogenesis in the biliary epithelium $[6,7]$. However, COX-2 protein expression was not observed both in noncancerous biliary epithelial cells and cancer cells, and p53 dysfunction appears unrelated to the multicentric origins of carcinogenesis in this patient. The only interesting histological finding we could identify was the concurrence of widespread mucosal dysplasia in the common bile duct; a dysplasia-carcinoma sequence has been assumed as the main route of carcinogenesis, like the adenoma-carcinoma sequence in familial adenomatous polyposis and colon carcinoma.

Thus the exact mechanism of carcinogenesis remains to be elucidated in this patient; however, many reports have offered clinical evidences of metachronous carcinoma which developed at the site of hepaticojejunostomy or at intrahepatic or terminal bile ducts a long time after the initial surgery [8]. Patients who have once experienced papillary carcinoma in the biliary tract might have a long-term risk of carcinogenesis.

Morphologically, second tumors usually display a papillary type similar to the primary tumor, and the depth of tumor is superficial without tumor invasion to neighboring organs. Aggressive surgical approach to the treatment of such tumors is technically possible and a rational therapeutic option that offers a chance of long-time survival for patients. Close monitoring for recurrence is warranted for early detection of tumors that might be effectively treated with repeated resection.

Table 1. Clinicohistopathological and immunohistochemical findings

\begin{tabular}{lllcl}
\hline Year & Organ & Gross appearance/histological type & p53 & COX2 \\
\hline 1979 & gallbladder & papillary carcinoma/papillotubular adenocarcinoma & + & - \\
& & noncancerous biliary mucosa/normal & - & - \\
1997 & liver & ICC/poorly differentiated adenocarcinoma & + & - \\
& cystic duct & papillary carcinoma/papillary adenocarcinoma & + & - \\
& extrahepatic bile duct & papillary carcinoma/papillary adenocarcinoma & - & - \\
& & biliary mucosa with widespread tiny granular lesions/severe & \\
& & dysplasia & - & - \\
2004 & liver & noncancerous biliary mucosa/normal & - & - \\
& & ICC/moderately differentiated tubular adenocarcinoma & - & - \\
& & noncancerous biliary mucosa/normal & - & - \\
\hline
\end{tabular}




\begin{tabular}{r|l|l|l} 
Case Reports $h$ Ch & $\begin{array}{l}\text { Case Rep Gastroenterol 2009;3:84-91 } \\
\text { Dol: } 10.1159 / 000208376\end{array}$ & Published online: April 15, 2009 & $\begin{array}{l}\text { I 2009 S. Karger AG, Basel } \\
\text { ISSN 1662-0631 } \\
\text { www.karger.com/crg }\end{array}$ \\
& & & \\
\hline
\end{tabular}

Fig. 1. a Microscopic findings of the small nodular lesion of the gallbladder. Epithelial cells proliferating with papillary and/or tubular pattern. $\mathrm{H} \& \mathrm{E}, \times 10$. b High-power view of the lesion shows nuclear atypia. Diagnosed as papillary carcinoma in situ. $\mathrm{H} \& \mathrm{E}, \times 40$.

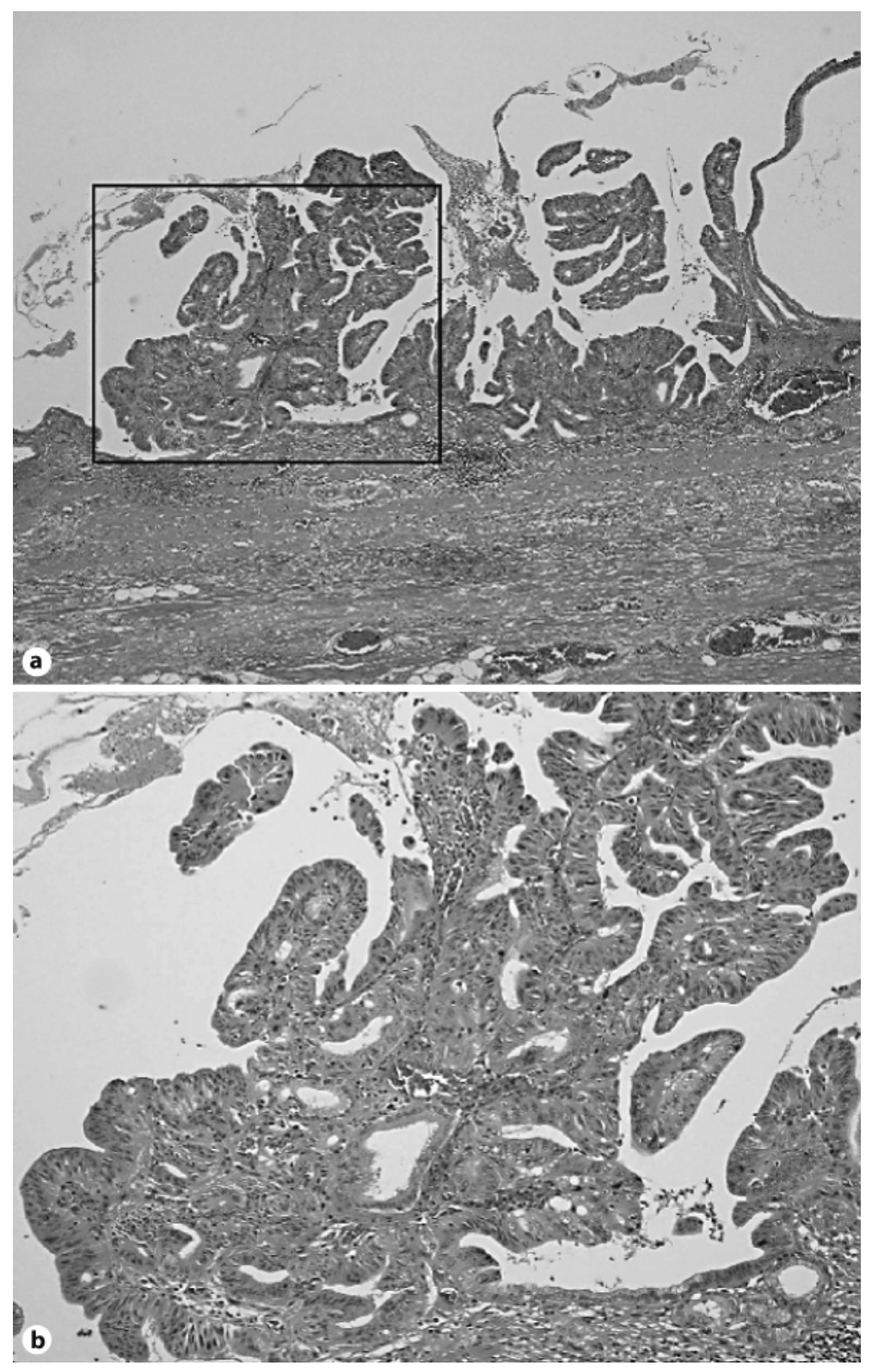




\begin{tabular}{r|l|l|l} 
Case Reports in & $\begin{array}{l}\text { Case Rep Gastroenterol 2009;3:84-91 } \\
\text { D01: 10.1159/000208376 }\end{array}$ & Published online: April 15, 2009 & $\begin{array}{l}\text { O 2009 S. Karger AG, Basel } \\
\text { ISSN 1662-0631 } \\
\text { www.karger.com/crg }\end{array}$ \\
\hline
\end{tabular}

Fig. 2. a Abdominal computed tomography shows a low-density mass (arrow) in the left hepatic lobe. b Endoscopic retrograde cholangiopancreatography demonstrates a tumor shadow (arrow) in the common bile duct.
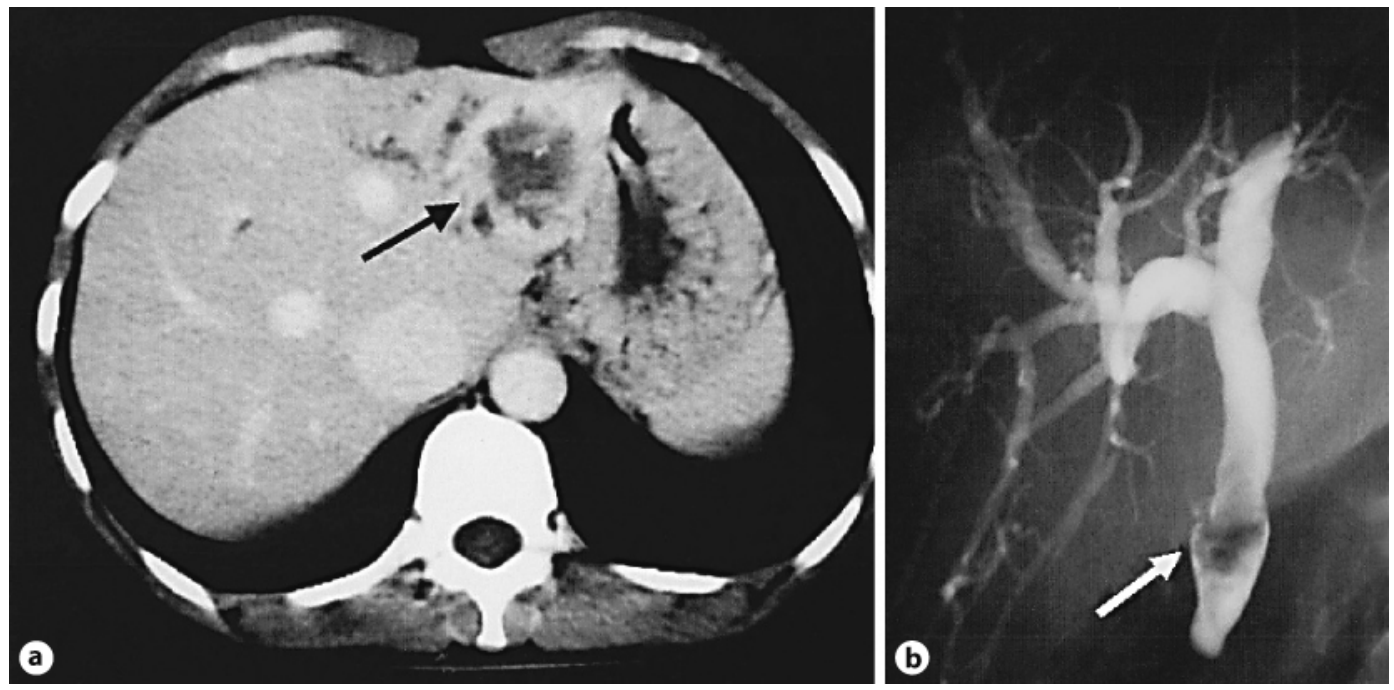


\begin{tabular}{r|l|l|l} 
Case Reports $/ \mathrm{h}$ & $\begin{array}{l}\text { Case Rep Gastroenterol 2009;3:84-91 } \\
\text { D0I: 10.1159/000208376 }\end{array}$ & Published online: April 15, 2009 & $\begin{array}{l}\text { O 2009 S. Karger AG, Basel } \\
\text { ISSN 1662-0631 } \\
\text { www.karger.com/crg }\end{array}$ \\
\hline
\end{tabular}

Fig. 3. a Microscopic view of the hepatic tumor showing poorly differentiated tubular adenocarcinoma and irregular shaped small glands infiltrating in the fibrous interstitium. b Microscopic view of the cystic duct tumor. Polypoid lesion measuring $18 \mathrm{~mm}$ in diameter was histologically identified as papillary adenocarcinoma. $\mathbf{c}$ In the mucosa of the intra- and extrahepatic biliary tract, foci of small papillary projections of the epithelium with slight nuclear atypia were widely spread.
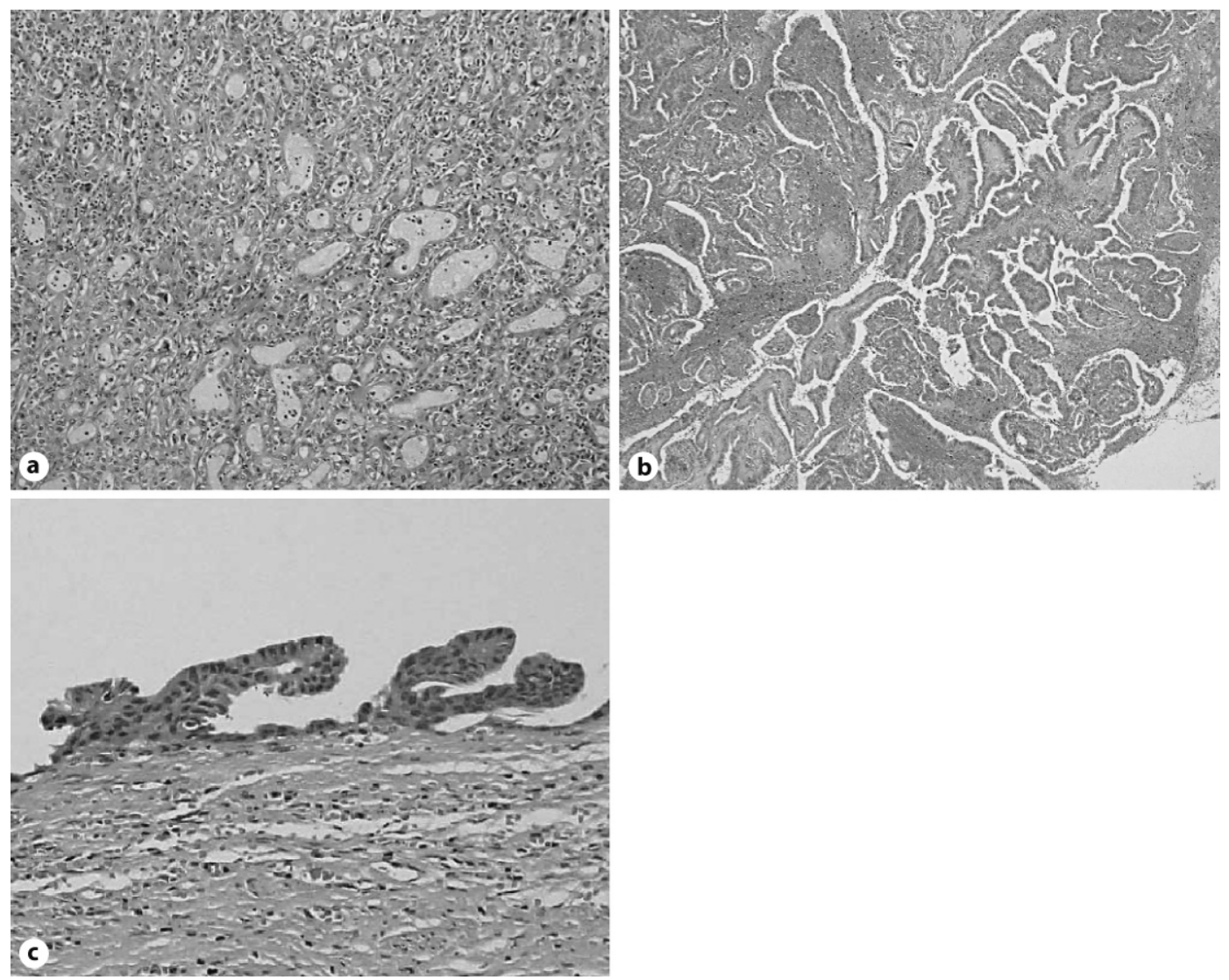


\begin{tabular}{r|l|l|l} 
Case Reports in & $\begin{array}{l}\text { Case Rep Gastroenterol 2009;3:84-91 } \\
\text { D0I: 10.1159/000208376 }\end{array}$ & Published online: April 15, 2009 & $\begin{array}{l}\text { O 2009 S. Karger AG, Basel } \\
\text { ISSN 1662-0631 } \\
\text { www.karger.com/crg }\end{array}$ \\
\hline
\end{tabular}

Fig. 4. a Cut surface of the resected liver at the third surgery showing a whitish, well-circumscribed tumor measuring $21 \times 19 \mathrm{~mm}$. b Histologically, moderately differentiated tubular adenocarcinoma with fused glands focally showed papillary growth pattern. H\&E, $\times 10$.

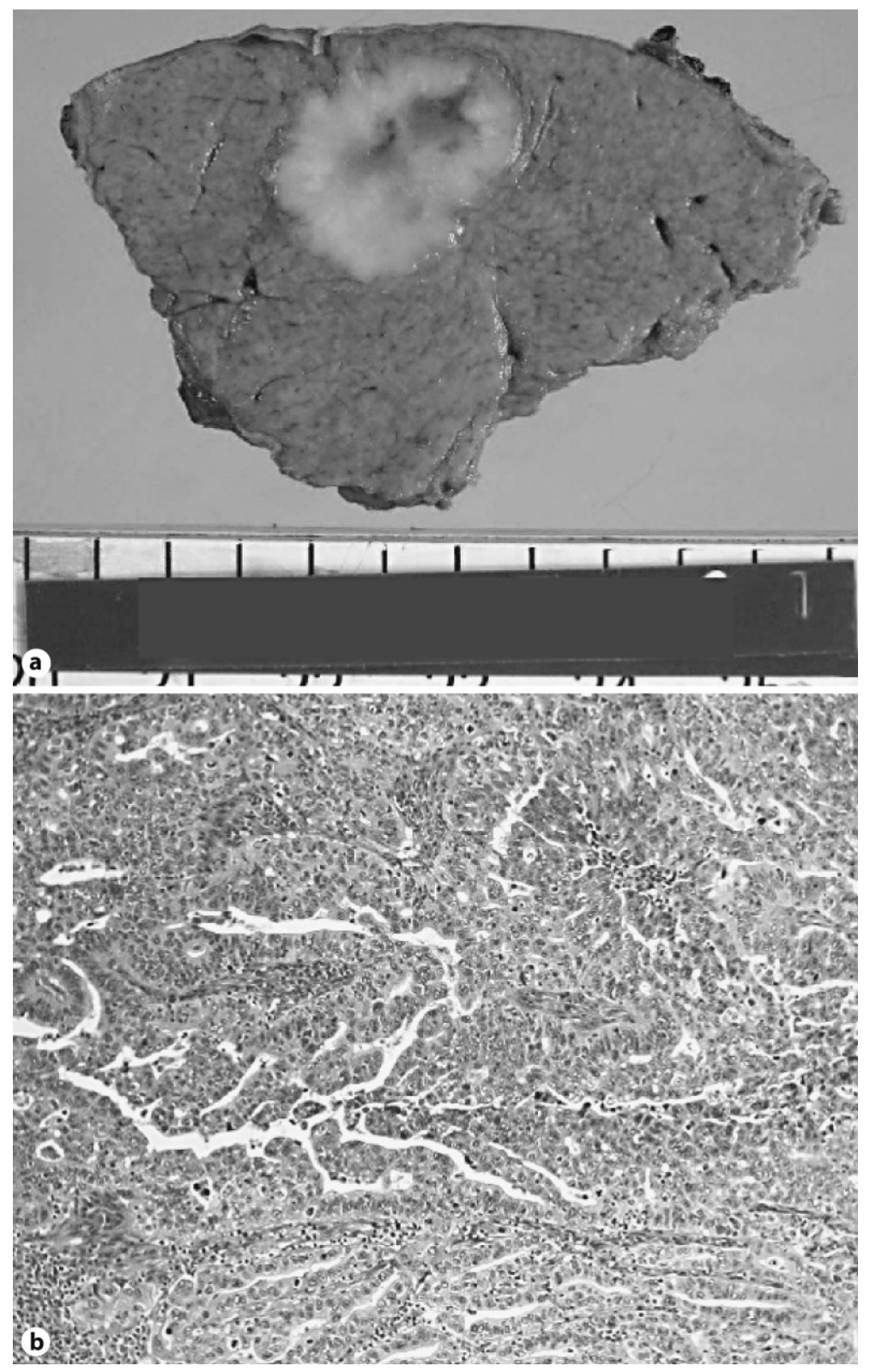




\section{References}

1 Todani T, Watanabe Y, Fujii T, Toki A, Uemura S, Koike Y: Congenital choledochal cyst with intrahepatic involvement. Arch Surg 1984;119:1038-1043.

2 Aoki H, Sugenoya H, Shimazu M: A clinical study on cancer of the bile duct associated with anomalous arrangements of the pancreaticobiliary ductal system: analysis of 569 cases collected in Japan. J Bil Panc 1987;8:1539-1551.

-3 Hasumi A, Matsui H, Sugioka A, Uyama I, Komori Y, Fujita J, Aoki H: Precancerous conditions of biliary tract cancer in patients with pancreaticobiliary muljunction: reappraisal of nationwide survey in Japan. J Hepatobiliary Pancreat Surg 2000;7:551-555.

-4 Sonoshita M, Takaku K, Sasaki N, Sugimoto Y, Ushikubi F, Narumiya S, Oshima M, Taketo MM: Acceleration of intestinal polyposis through prostaglandin receptor EP2 in Apc(Delta 716) knockout mice. Nat Med 2001;7:1048-1051.

5 Bresalier RS: Chemoprevention comes to clinical practice: COX-2 inhibition in familial adenomatous polyposis. Gastroenterology 2000;119:1797-1798.

-6 Hanada K, Itoh M, Fujii K, Tsuchida A, Ooishi H, Kajiyama G: K-ras and p53 mutation in stage I gallbladder carcinoma with an anomalous junction of the pancreaticobiliary duct. Cancer 1996;77:452-458.

-7 Matsubara T, Funabiki T, Jinno O, Sakurai Y, Hasegawa S, Imazu H, Ochiai M: p53 gene mutations and overexpression of p53 product in cancerous and noncancerous biliary epithelium in patients with pancreaticobiliary maljunction. J Hepatobiliary Pancreat Surg 1999;6:286-293.

-8 Tsuchida A, Kasuya K, Endo M, Saito H, Inoue K, Nagae I, Aoki T, Koyanagi Y: High risk of bile duct carcinogenesis after primary resection of a congenital biliary dilatation. Oncol Rep 2003;10:1183-1187. 